Review

\title{
Fish, Mercury, Selenium and Cardiovascular Risk: Current Evidence and Unanswered Questions
}

\section{Dariush Mozaffarian}

Division of Cardiovascular Medicine and Channing Laboratory, Brigham and Women's Hospital and Harvard Medical School, and Departments of Epidemiology and Nutrition, Harvard School of Public Health, Boston, MA, USA; Tel.: +1-617-432-2887; Fax: +1-617-432-2435;

E-Mail: dmozaffa@hsph.harvard.edu

Received: 22 May 2009 / Accepted: 4 June 2009 / Published: 23 June 2009

\begin{abstract}
Controversy has arisen among the public and in the media regarding the health effects of fish intake in adults. Substantial evidence indicates that fish consumption reduces coronary heart disease mortality, the leading cause of death in developed and most developing nations. Conversely, concerns have grown regarding potential effects of exposure to mercury found in some fish. Seafood species are also rich in selenium, an essential trace element that may protect against both cardiovascular disease and toxic effects of mercury. Such protective effects would have direct implications for recommendations regarding optimal selenium intake and for assessing the potential impact of mercury exposure from fish intake in different populations. Because fish consumption appears to have important health benefits in adults, elucidating the relationships between fish intake, mercury and selenium exposure, and health risk is of considerable scientific and public health relevance. The evidence for health effects of fish consumption in adults is reviewed, focusing on the strength and consistency of evidence and relative magnitudes of effects of omega-3 fatty acids, mercury, and selenium. Given the preponderance of evidence, the focus is on cardiovascular effects, but other potential health effects, as well as potential effects of polychlorinated biphenyls and dioxins in fish, are also briefly reviewed. The relevant current unanswered questions and directions of further research are summarized.
\end{abstract}

Keywords: fish; mercury; selenium; cardiovascular disease; review 


\section{Introduction}

Controversy is present among the public and in the media regarding the health effects of fish consumption. Considerable evidence indicates that consumption of fatty fish reduces coronary heart disease (CHD) mortality [1] the leading cause of death in developed and most developing nations. On the other hand, concerns regarding potential harm from exposure to mercury [2-6], a heavy metal present in some fish species, have tempered the perception of fish as a healthy food. Very high levels of mercury exposure are known to cause sensorimotor symptoms in adults, which are often reversible when mercury exposure is reduced [7-9]. However, for the great majority of individuals, the main concern is the potential health effects of chronic low-level mercury exposure from modest fish consumption. Seafood species are also rich in selenium, an essential dietary trace element that plays an important role in antioxidant defense systems and may protect against both cardiovascular disease (CVD) and the toxic effects of mercury. A protective effect of selenium could directly inform recommendations relating to both optimal selenium intake and the potential impact of mercury exposure from fish consumption in selenium-replete vs. selenium-deficient populations. Because fish consumption appears to have significant health benefits, elucidating the relationship between fish intake, mercury exposure, and health risk is of considerable scientific and public health importance. The evidence for health effects of fish consumption in adults is reviewed, particularly the strength and consistency of evidence and relative magnitudes of cardiovascular effects of marine omega-3 polyunsaturated fatty acids ( $n-3$ PUFA), mercury, and selenium in fish. Other potential health effects, including potential effects of polychlorinated biphenyls (PCBs) and dioxins in fish, are also briefly reviewed. This article does not consider possible cardiovascular benefits of plant-based omega-3 fatty acids, which have been reviewed elsewhere [10]. This review also focuses on health effects in adults - the potential effects on infant neurodevelopment, and corresponding recommendations for women who are or may become pregnant, have been reviewed elsewhere $[1,11,12]$.

\section{Fish and Cardiovascular Risk}

Consumption of fish or fish oil favorably affects several cardiovascular risk factors (Figure 1) [13-24]. Changes in most risk factors are generally evident within weeks of changes in consumption and may result from altered cell membrane fluidity and receptor responses following incorporation of n-3 PUFA into cell membrane phospholipids [25,26] as well as direct binding of n-3 PUFA to cytosolic receptors that regulate gene transcription [27]. These physiologic effects of $n-3$ PUFA have varying dose-responses and time-responses of effect [1]. For example, at typical dietary intakes ( $<1 \mathrm{~g} / \mathrm{d}$ of n-3 PUFA), anti-arrhythmic effects appear to predominate, with such effects reducing the risk of cardiac death within weeks to months. At higher levels of consumption, maximum antiarrhythmic benefits appear to have been achieved, but now other physiologic effects of n-3 PUFA consumption (Figure 1) may begin to influence other clinical outcomes, such as stroke or nonfatal CVD events. Time courses of benefit also vary; for instance, some of these effects (such as triglyceride-lowering) might require months or years of consumption before an impact on incidence of clinical outcomes are evident. These benefits on intermediate risk factors are compelling, but inference for health effects of an exposure on chronic disease outcomes requires confirmation in studies of actual disease endpoints in humans. 
Figure 1. Schema of physiologic effects of n-3 PUFA consumption. The strength of effect denotes the relative impact of n-3 PUFA intake on clinical risk by means of the physiologic effect (e.g., triglyceride-lowering), whereas the time course to alter clinical events denotes the expected duration of intake for the benefits on the physiologic effect to be manifested in improved disease outcomes. For instance, the dose-response for anti-arrhythmic effects appears to be initially steep with a subsequent plateau, and effects on disease outcomes may be seen in weeks to months, whereas the dose-response for triglyceride-lowering is more gradual and monotonic, and effects on disease outcomes may require months to years of intake. Potentially important effects of n-3 PUFA on endothelial, autonomic, anti-inflammatory, and diastolic responses are not shown because dose- and time-responses of these effects are less well-established. Physiologic effects are not necessarily exclusive: e.g., anti-arrhythmic effects may be partly mediated by effects on blood pressure (BP) or heart rate. Reproduced with permission from Mozaffarian and Rimm [1].

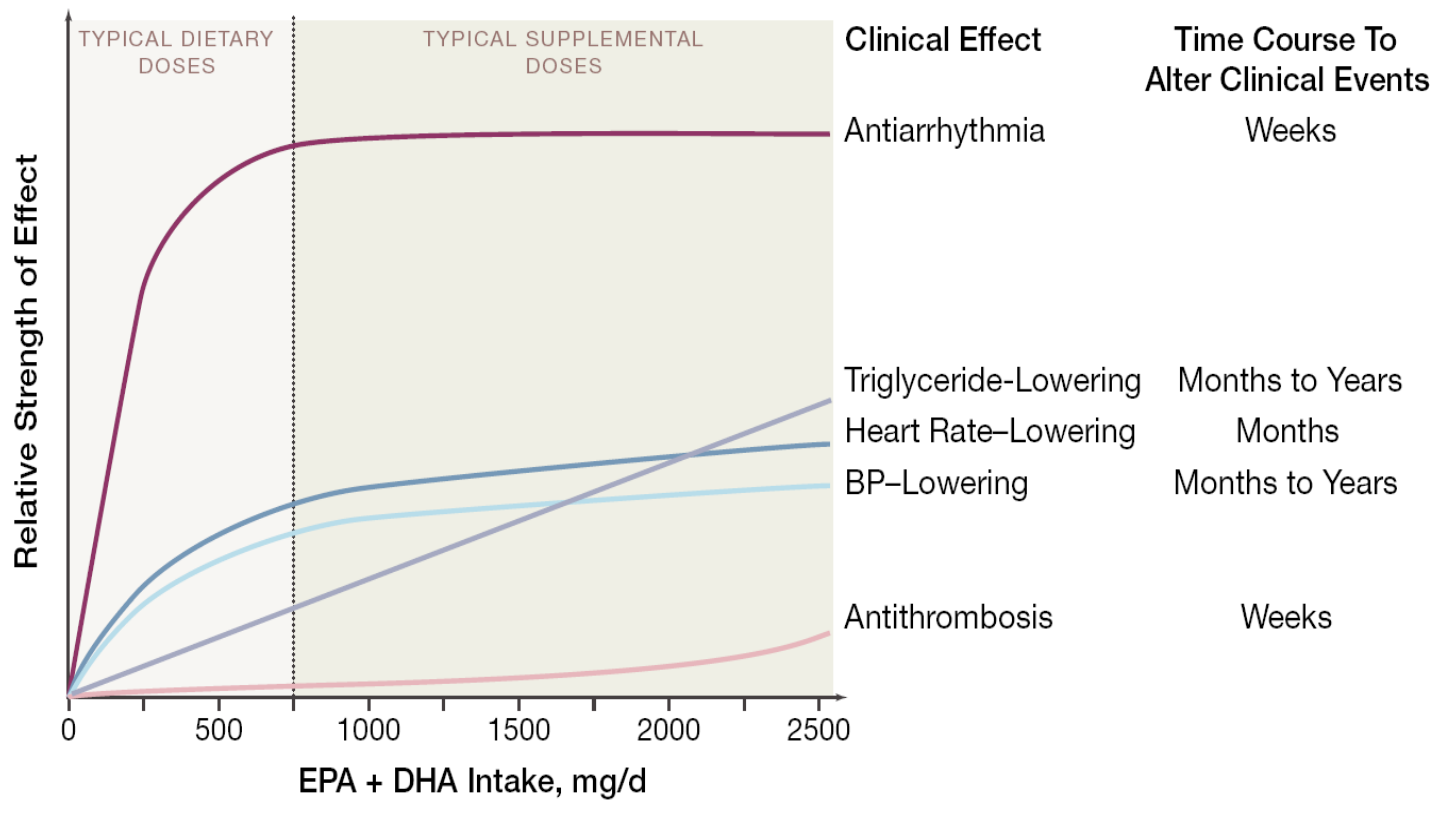

This evidence exists. Results of case-control studies, prospective cohort studies, and randomized controlled trials each indicate that modest consumption of fish or fish oil lowers the risk of cardiac mortality, specifically CHD death and sudden cardiac death [1]. This effect appears to be nonlinear: compared with little or no intake, modest consumption $(\sim 250 \mathrm{mg} / \mathrm{d})$ of the marine $\mathrm{n}-3$ PUFA eicosapentaenoic acid (EPA) and docosahexaenoic acid (DHA) significantly lowers risk of cardiac mortality, whereas higher intakes do not substantially further lower risk, suggesting a threshold of effect [1]. The similarity of findings between observational studies of fish consumption and randomized controlled trials of n-3 PUFA supplementation suggests that, at least for cardiac mortality, much of the benefit of fish intake is related to the n-3 PUFA content. Consistent with this, when different types of fish meals are considered, lower risk is more strongly related to intake of fatty (oily or dark meat) fish, compared with lean (white meat) fish [28,29]. The quantity of fish servings needed to consume an average of $250 \mathrm{mg} / \mathrm{d} \mathrm{EPA}+\mathrm{DHA}$ varies depending on the particular fish species, but for fatty fish (e.g., anchovies, herring, salmon, sardines, trout, white tuna) is $\sim 1-2$ servings/week (Figure 2). 
Figure 2. The number of $3.5 \mathrm{oz}(100 \mathrm{~g})$ fish servings per week needed to provide an average of $250 \mathrm{mg}$ /day of the marine $\mathrm{n}-3$ polyunsaturated fatty acids eicosapentaenoic acid (EPA) and docosahexaenoic acid (DHA). Based on data from Mozaffarian and Rimm [1].

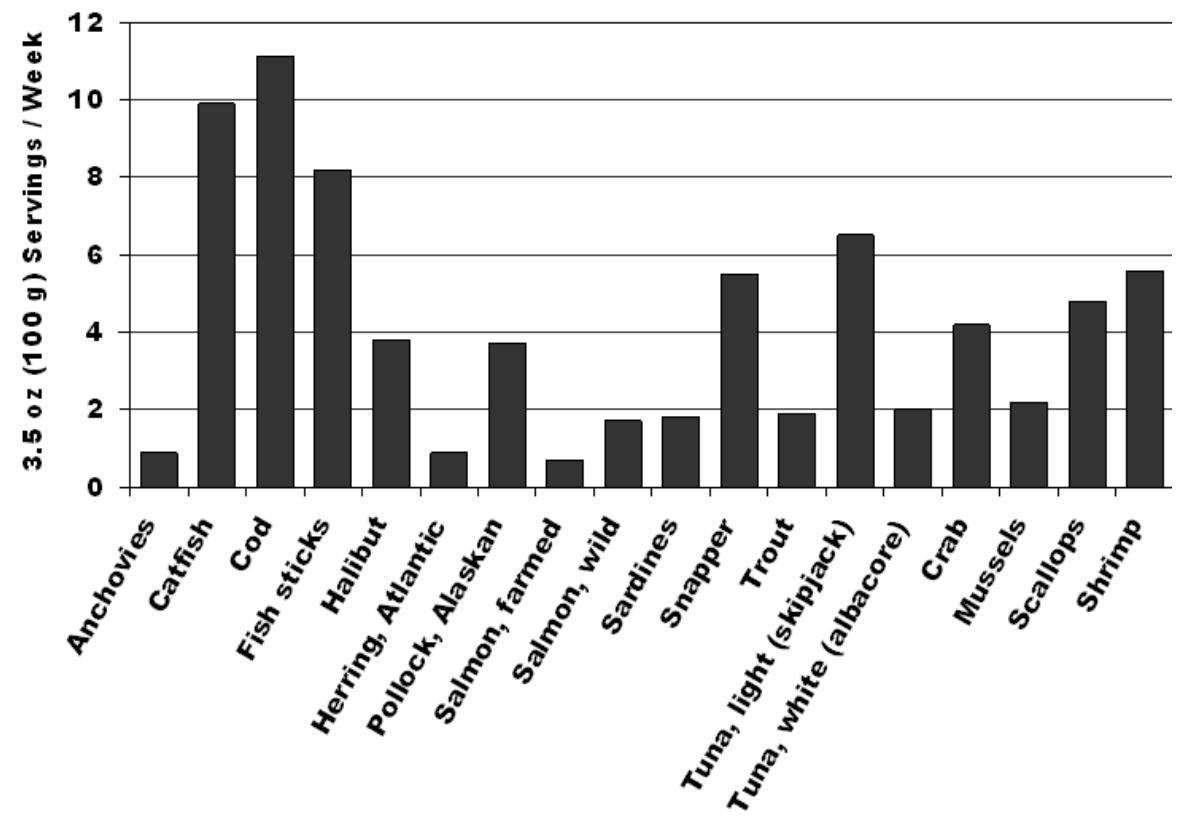

The strength and consistency of the evidence, and the magnitude of the benefit, for lowering of cardiac mortality by fish consumption are each notable. The risk reduction is supported by consistent evidence from experimental studies and randomized trials investigating effects of fish or fish oil consumption on cardiovascular risk factors; case-control studies evaluating fish consumption or objective biomarkers of n-3 PUFA intake and risk of cardiac outcomes; prospective studies of habitual fish consumption and cardiac outcomes that have followed hundreds of thousands of people for many years across a range of countries; and randomized controlled trials of fish or fish oil consumption that have enrolled thousands of subjects and demonstrated reductions in clinical events [1]. The magnitude of the benefit is also considerable: pooling of the prospective studies and controlled trials indicates that, compared with no intake, modest consumption ( $250 \mathrm{mg} /$ day [21/4 calories/day] of EPA+DHA, equivalent to $\sim 1-2$ servings/week of fatty fish) lowers risk of CHD mortality by $36 \%$ [1]. Analyses restricted to populations free of established heart diease (i.e., primary prevention) demonstrate similar results [30]. Fish intake may also reduce the risk of other cardiovascular and noncardiovascular outcomes, including but not limited to nonfatal heart attacks [31], ischemic stroke [32], atrial fibrillation [33], cognitive decline [34], and depression [35], but the evidence for these benefits is not yet as robust as for CHD death [1].

\section{Mercury and Cardiovascular Risk}

Mercury is a highly reactive heavy metal that is rarely found as a free element in Nature. In its elemental form, it is emitted from coal-burning electric power plants and used in chlorine production, dental amalgams, thermometers, and batteries [7,36]. Released into the air, it cycles from rain into streams, lakes, and oceans where it is converted by microorganisms into organic methylmercury 
(MeHg). Smaller amounts of inorganic mercury naturally in the environment (e.g., from volcanoes) may also be converted by these microorganisms to $\mathrm{MeHg}$. When these microorganisms are ingested, $\mathrm{MeHg}$ bioaccumulates in the food chain from smaller creatures to larger predators, with tissue concentrations depending on the level of local contamination and on the size, lifespan, and predatory nature of each creature. Thus, MeHg levels tend to be higher in large, long-lived predators (e.g., shark, swordfish, king mackerel, tilefish); intermediate in medium-sized predators (e.g., trout, snapper); and lowest in short-lived (e.g., salmon) or smaller (e.g., shrimp, clams) species [1].

By strongly binding to sulfhydryl groups, mercury can alter the activity of a variety of enzymes, ion channels, and receptors [3,7]. In considering public health effects of chronic low-level exposure, the primary mercury species of interest is $\mathrm{MeHg}$, which is more reactive and potentially toxic than elemental or inorganic mercury [7,36-38]. Elemental mercury is oxidized to mercuric ion, which does not readily cross some tissue barriers. Also, inorganic mercury is poorly absorbed in the gastrointestinal tract, limiting potential toxicity. In contrast, $\mathrm{MeHg}$ is readily absorbed in the gastrointestinal system and actively transported into tissues by a widely distributed amino acid carrier protein following the formation of a methylmercury-cysteine complex. Thus, compared with elemental or inorganic mercury, $\mathrm{MeHg}$ is more toxic at lower levels of exposure [7]. Additionally, with the exception of industrial accidents or occupational exposures to organic mercury, the major source of mercury exposure in humans is MeHg from fish [7,36,39,40]. Accordingly, the Mercury Study Report to Congress concluded, "Assessment of health endpoints, dose-response, and exposure suggests that methylmercury is the chemical species of major concern [7]."

Given their slow growth, mercury levels in toenails or hair provide the best biomarkers of chronic mercury exposure. Toenail mercury levels correlate with usual fish intake and, due to stability of most individuals' dietary habits, are reproducible over time $(r=0.56$ for toenail mercury samples obtained six years apart) [41,42]. This stability is similar to correlations of 0.6 - 0.7 typically observed, over a similar time interval, for widely used epidemiologic measures such as blood pressure [43]. Whereas both organic and inorganic mercury species contribute to total mercury levels, in the absence of unusual occupational or environmental exposures to inorganic mercury, $\mathrm{MeHg}$ from fish intake is the major determinant of variation in total mercury levels in hair and toenails. For example, the correlation between total mercury and $\mathrm{MeHg}$ levels in hair is 0.99 [44], and in toenails, this correlation is 0.97 (unpublished observation, in collaboration with Dr. Shade, Quicksilver Scientific, LLC, Lafayette, CO).

High exposure to mercury (often much higher than the U.S. reference dose) causes paresthesias, ataxia, and sensory symptoms in adults, which are often reversible when mercury exposure is reduced [7-9]. However, few individuals are exposed to such doses, and thus the major public health concern for the general population is the potential health effect of chronic low-level mercury exposure that could result from modest (up to several servings per week) fish consumption. For example, because such chronic low-level mercury exposure may have subtle effects on the developing brain in infants, the U.S. Food and Drug Administration and U.S. Environmental Protection Agency have issued specific recommendations regarding consumption of a few specific fish species to minimize mercury exposure in women who are or may become pregnant, nursing mothers, and young children [12,36].

Similar recommendations have not been released for the general population, because it is less clear that chronic low-level mercury exposure has significant health effects in adults. For example, outside of the sensitive period of brain development in the first years of life, current evidence is insufficient to 
conclude that chronic low-level mercury exposure has appreciable neurologic effects. As previously reviewed [1,11], in populations exposed to mercury from fish consumption, no clinical neurologic effects of mercury exposure are seen (excepting individuals with very high consumption, more than several servings per week, of fish highest in mercury [9]) and evidence for subclinical neurologic effects detectable with specialized testing is inconsistent [45-49]. Conversely, more consistent evidence suggests that fish consumption may favorably affect clinical neurologic events in adults, including ischemic stroke [32], cognitive decline and dementia [34], and depression and other neuropsychiatric disorders $[35,50,51]$. Thus, the balance of evidence does not suggest strong harm of fish consumption on neurologic outcomes in adults, but rather suggests significant potential benefits.

The most concerning potential health effects of chronic low-level mercury exposure in adults are on CVD risk and outcomes. In vitro and animal-experimental studies [2,3,6,52-61], as well as some observational studies of intermediate risk factors in humans [62-67], suggest that mercury has a variety of effects that could increase cardiovascular risk (Table 1).

Table 1. Experimentally-observed effects of mercury which may increase CVD risk.

\author{
Systemic Effects \\ Promotion of free radicals and reactive oxygen species \\ Increased lipid (e.g., LDL cholesterol) peroxidation \\ Promotion of blood coagulation (clotting) \\ Inhibition of endothelial cell migration \\ Direct Cardiovascular Effects \\ Reduction in myocardial contractile force \\ Increased calcium release from myocardial sarcoplasmic reticulum \\ Reduction in left ventricular myosin ATPase activity \\ Decreased heart rate variability and increased blood pressure
}

Inhibition of antioxidant systems (glutathione peroxidase, catalase, superoxide dismutase)

While these experimental results and observational studies of intermediate risk factors are suggestive, investigation of actual disease endpoints in humans provides the best evidence to confirm potential effects of an exposure on chronic disease. Six studies have reported on the relations between mercury exposure and CVD endpoints in humans (Table 2) [68-73]. Among men in Kuopio, Finland, those in the highest third of hair mercury content $(\geq 2.03 \mathrm{ug} / \mathrm{g}$ ) had $66 \%$ higher risk of acute coronary syndromes compared to men in the lower third $(<0.84 \mathrm{ug} / \mathrm{g})$ [72]. In two prospective studies in Sweden $[68,69]$, higher blood mercury levels were not significantly associated with CVD risk. In a retrospective case-control study in Europe, men in the highest two quintiles of toenail mercury content (median levels 0.36 and $0.66 \mathrm{ug} / \mathrm{g}$, respectively) had $\sim 2$-fold higher risk of nonfatal myocardial infarction, compared to men in the lowest fifth $(0.11 \mathrm{ug} / \mathrm{g})$ [70]. In a prospective study among U.S. men, toenail mercury concentrations were not significantly associated with CHD risk, even in the highest quintile (median level $1.34 \mathrm{ug} / \mathrm{g}$ ) [71]. Finally, in a large prospective study in Sweden, erythrocyte mercury levels were not associated with risk of stroke [73]. 
Table 2. Prior studies of mercury and cardiovascular events in humans.

\begin{tabular}{|c|c|c|c|c|c|c|}
\hline Author, Year & Design & Country & Exposure & Outcome & $\begin{array}{l}\text { No. of } \\
\text { Cases }\end{array}$ & $\begin{array}{c}\text { Relative Risk (5\% CI) } \\
\text { with High Mercury * }\end{array}$ \\
\hline Ahlqwist, 1999 & $\begin{array}{l}\text { Prospective } \\
\text { cohort }\end{array}$ & Sweden & $\begin{array}{l}\text { Serum } \\
\text { mercury }\end{array}$ & $\begin{array}{l}\text { Total myocardial } \\
\text { infarction, Stroke }\end{array}$ & 87,77 & $\begin{array}{l}\mathrm{RR}=0.71(0.40,1.26) \dagger \\
\text { for } \mathrm{MI} ; \mathrm{RR}=\mathrm{NS} \text { (data } \\
\text { not reported) for stroke }\end{array}$ \\
\hline Hallgren, 2001 & $\begin{array}{l}\text { Prospective } \\
\quad \text { (nested) } \\
\text { case-control }\end{array}$ & Sweden & $\begin{array}{l}\text { Erythrocyte } \\
\text { mercury }\end{array}$ & $\begin{array}{l}\text { Total myocardial } \\
\text { infarction }\end{array}$ & 78 & $\begin{array}{l}\mathrm{RR}=0.51 \\
(0.21,1.24)\end{array}$ \\
\hline Guallar, 2002 & $\begin{array}{l}\text { Retrospective } \\
\text { case-control }\end{array}$ & $\begin{array}{c}8 \text { European } \\
\text { countries } \\
\text { and Israel }\end{array}$ & $\begin{array}{l}\text { Toenail } \\
\text { mercury }\end{array}$ & $\begin{array}{l}\text { Nonfatal } \\
\text { myocardial } \\
\text { infarction }\end{array}$ & 684 & $\begin{array}{l}\mathrm{RR}=2.16 \\
(1.09,4.29)\end{array}$ \\
\hline Yoshizawa, 2002 & $\begin{array}{l}\text { Prospective } \\
\text { (nested) } \\
\text { case-control }\end{array}$ & USA & $\begin{array}{l}\text { Toenail } \\
\text { mercury }\end{array}$ & $\begin{array}{c}\text { Total myocardial } \\
\text { infarction }+ \\
\text { coronary } \\
\text { revascularization }\end{array}$ & 470 & $\begin{array}{l}\mathrm{RR}=1.03 \\
(0.65,1.65)\end{array}$ \\
\hline Virtanen, 2005 & $\begin{array}{l}\text { Prospective } \\
\text { cohort }\end{array}$ & Finland & $\begin{array}{l}\text { Hair } \\
\text { mercury }\end{array}$ & $\begin{array}{c}\text { Total acute } \\
\text { coronary events }\end{array}$ & 282 & $\begin{array}{l}\mathrm{RR}=1.66 \\
(1.20,2.29)\end{array}$ \\
\hline Wennberg, 2007 & $\begin{array}{l}\text { Prospective } \\
\quad \text { (nested) } \\
\text { case-control }\end{array}$ & Sweden & $\begin{array}{l}\text { Erythrocyte } \\
\text { mercury }\end{array}$ & Stroke & 369 & $\begin{array}{c}\mathrm{RR}=0.99(0.93,1.06) \\
\text { in men; } \mathrm{RR}=1.00 \\
(0.94,1.08) \text { in women }\end{array}$ \\
\hline
\end{tabular}

*Multivariable-adjusted relative risk (RR) comparing the highest vs. the lowest category of mercury levels, except for Wennberg et al. for which the RR corresponds to each one ng/g increase in erythrocyte mercury. $\dagger$ Personal communication (Calle Bengtsson, June 6, 2006). NS = nonsignificant.

Each of these studies had important potential limitations. In the Kuopio study, higher CHD risk was not seen until hair mercury levels exceeded $\sim 2.0 \mathrm{ug} / \mathrm{g}$, a level higher than the $95^{\text {th }}$ percentile of hair mercury levels among U.S. women of childbearing age $(1.73 \mathrm{ug} / \mathrm{g})$, nearly double the $90^{\text {th }}$ percentile $(1.11 \mathrm{ug} / \mathrm{g})$, and more than 10 -fold higher than the average population exposure $(0.19 \mathrm{ug} / \mathrm{g})$. At hair mercury levels below $\sim 2.0 \mathrm{ug} / \mathrm{g}$ in the Kuopio study, no significant relationships with CHD risk were seen; indeed, for CVD death and CHD death, individuals with hair mercury levels between 0.84 and $2.03 \mathrm{ug} / \mathrm{g}$ had trends toward lower risk than individuals with lower hair mercury levels. In the two earliest Swedish studies, relatively few events occurred, limiting statistical power. Ahlqwist et al. assessed mercury exposure in serum, which would reflect inorganic mercury from dental amalgams in addition to methylmercury from fish. Guallar et al. was a retrospective study in which only survivors of myocardial infarction were included; this could underestimate health benefits of fish consumption due to likely stronger benefits for fatal cardiac events (e.g., due to anti-arrhythmic effects), that were not included. In addition, more than one-third of eligible controls did not participate in this retrospective study, raising concerns for selection bias (i.e., the participating controls may not have been representative of the study base population giving rise to the cases). The U.S. cohort was large, prospective, and utilized toenail mercury, each of which would increase validity of results. Conversely, nearly 60 percent of participants were dentists, in whom mercury exposures would include both $\mathrm{MeHg}$ 
from fish consumption and inorganic mercury from working with mercury-containing dental amalgams [40]; thus, toenail mercury levels represented the combination of these exposures, which might have reduced the ability to detect associations with disease risk due to lower toxicity of inorganic mercury, compared with $\mathrm{MeHg}$. When results were limited to the nondentists, trends toward higher CHD risk were seen with higher mercury levels, but results were not statistically significant due to fewer numbers of subjects in this subset [71].

Thus, the results of studies of mercury and cardiovascular events have been inconsistent, with only six published studies of this relationship and potential important limitations to each study. A meta-analysis of the five studies that evaluated CHD events (Figure 3) indicated no significant association between higher mercury exposure and risk of CHD (pooled $\mathrm{RR}=1.12,95 \% \mathrm{CI}=0.71-1.75$ ) [1] Most of these studies also excluded women, in whom CVD causes more deaths than the next seven causes of death combined, and did not evaluate stroke, the second leading cause of CVD morbidity and mortality [74]. Thus, the effect of mercury exposure on CVD risk has not been adequately studied, and U.S. regulatory agencies have identified this as a significant area of uncertainty requiring further attention [5]. Other quantitative analyses of risks and benefits of fish consumption also concluded that the current data is insufficient to quantitate the extent to which mercury affects CVD risk, and that the published evidence is also qualitatively ambiguous [75].

Figure 3. Meta-analysis of studies of mercury exposure and risk of coronary heart disease (CHD). Relative risk (-) and 95\% CIs (-) are shown comparing the highest to the lowest quantile of mercury exposure after adjustment for other risk factors. Adapted from Mozaffarian and Rimm [1].

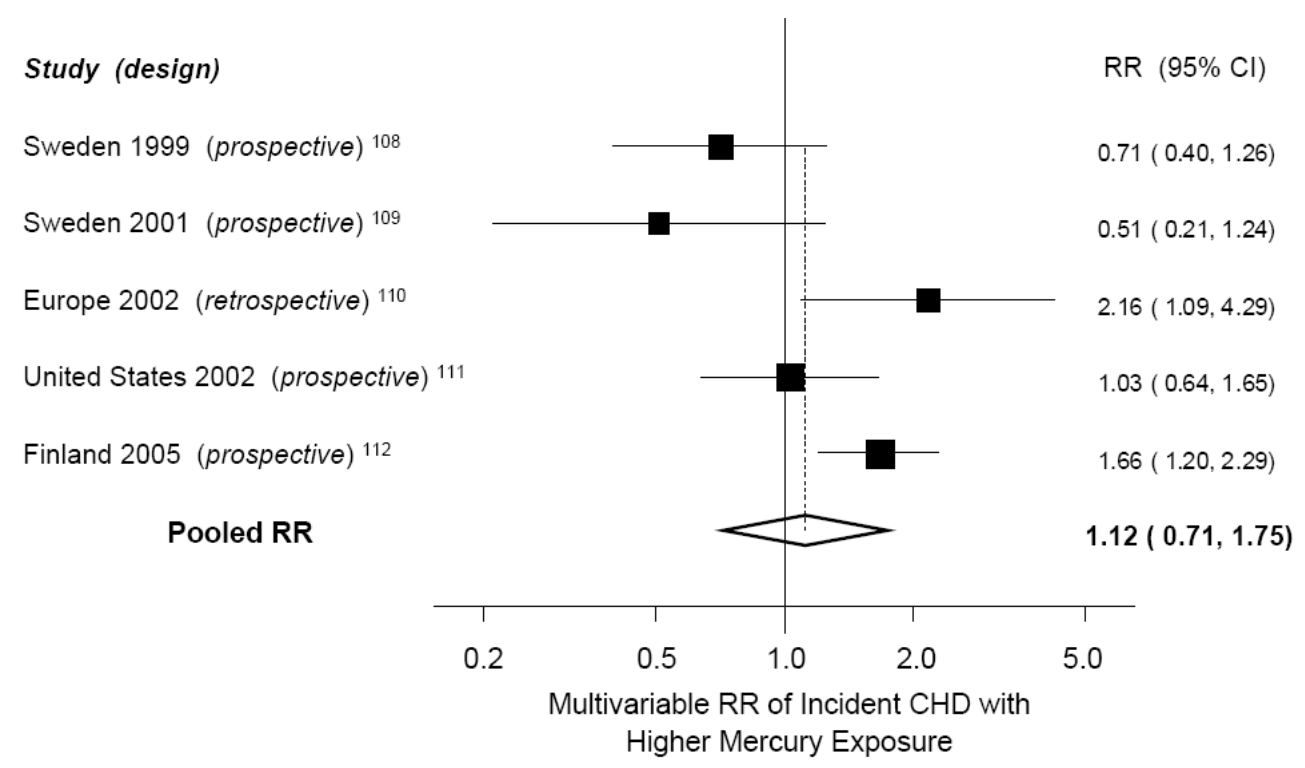

Notably, even if chronic mercury exposure were to increase CVD risk, the most important question for an individual decision regarding fish intake would be the tipping point of the relative harm from mercury vs. benefit from n-3 PUFA in the fish [76]. In other words, at what concentration of mercury, vs. content of n-3 PUFA, might the presence of $\mathrm{MeHg}$ change the health effects of fish consumption from net benefit to harm? Some data is available to help answer this question. First, in the two studies that observed higher cardiovascular risk with higher vs. lower mercury levels, the net relationship between overall fish consumption and CHD risk was still protective [70,72,77]. This suggests that, on 
average, fish consumption lowers CVD risk even in populations in which relative adverse effects of mercury were identified. Thus, the remaining uncertainty is: does this average beneficial effect of fish consumption differ at some level of mercury exposure? Unfortunately, most prior studies have not evaluated this potential interaction. The Kuopio investigators did report the interaction between effects of fish consumption, as reflected by serum n-3 PUFA levels, and effects of mercury exposure, as measured in hair [77]. Whether mercury levels were higher or lower, greater n-3 PUFA consumption was still associated with lower risk of CHD - higher mercury exposure simply lessened the slope of this benefit, but did not cause higher net risk (Figure 4). These findings suggest that, on average, (1) MeHg in fish may lessen the benefits of fish intake - a finding that has major implications for regulatory decisions regarding control of mercury emissions, because greater public health benefit may be derived from fish consumption if mercury levels were decreased; but (2) even consumption of mercury-containing fish provides some cardiovascular benefit compared with no fish consumption at all - a finding has major implications for an individual's decision to consume or not consume a particular fish meal that contains mercury. Further investigation of this potential interaction, including both higher and lower ranges of both n-3 PUFA and mercury exposure, is clearly warranted.

Figure 4. The interaction between exposure to n-3 PUFA and mercury from fish consumption. Serum docosahexaenoic acid (DHA) and docosopentaenoic acid (DPA) and hair mercury were measured in 1,871 participants who were prospectively followed for fatal or nonfatal acute coronary heart disease (CHD) [77]. Greater fish consumption (reflected by higher serum n-3 PUFA levels) was associated with lower CHD risk whether mercury exposure was high (> $2.0 \mathrm{ug} / \mathrm{g}$, representing the highest tertile of exposure) or low $(<2.0 \mathrm{ug} / \mathrm{g}$, representing the lowest two tertiles of exposure). However, the slope of this benefit was different: the higher relative risk of CHD $(R R=1.66)$ seen with higher mercury exposure in this study reflects, in essence, the difference in slope between these two lines. Thus, those with higher mercury exposure had less relative benefit - but not net harm - from higher fish consumption.

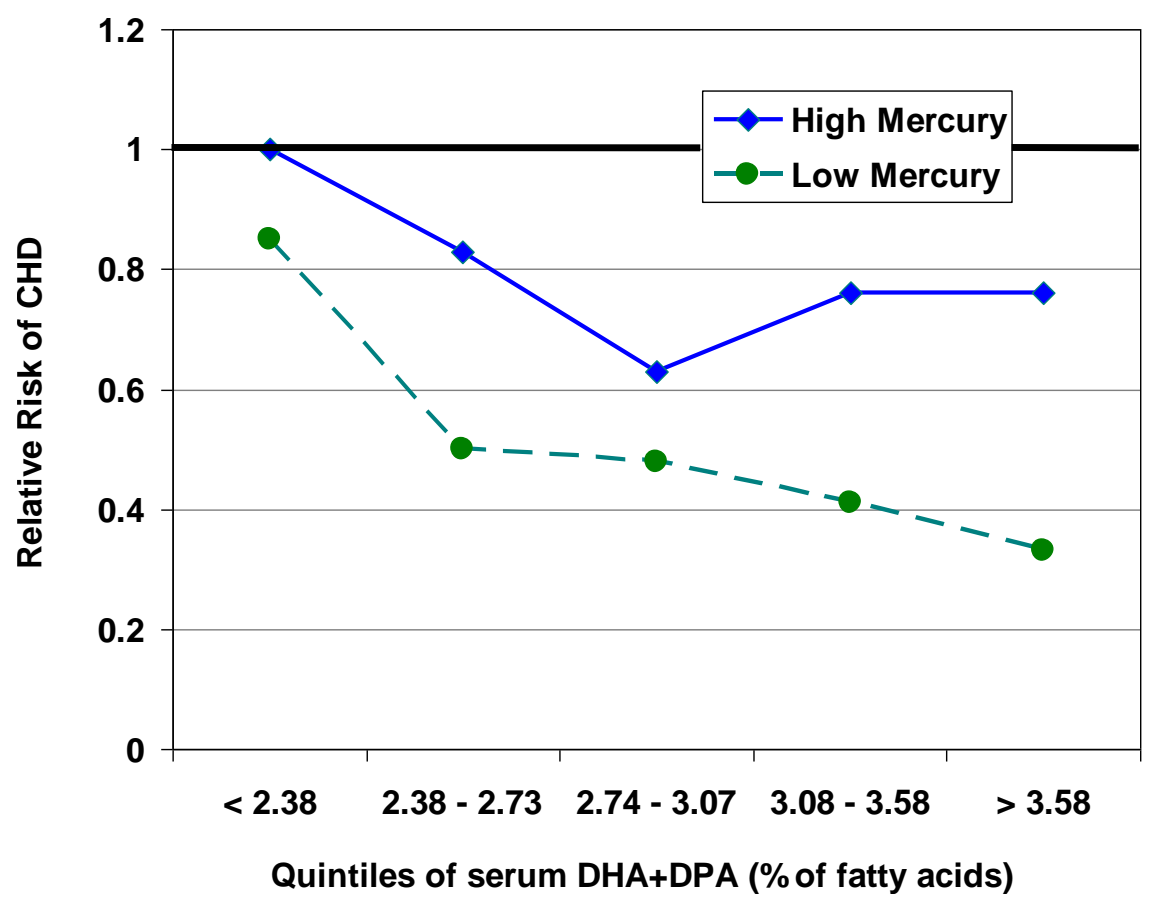




\title{
4. Selenium and Cardiovascular Risk
}

Selenium, an essential dietary trace mineral, is a critical component of numerous selenoproteins in humans [78-80]. Food sources include fish and other seafood, red meat, eggs, chicken, and liver [81]. Wheat germ, brewer's yeast, grains, and some vegetables may also be good sources, depending on the soil selenium concentration in which these crops were grown, that can vary substantially across different geographic regions [78,81]. Selenoproteins are important components of several antioxidant systems (e.g., glutathione peroxidase) that actively protect against damage from free radicals and reactive oxygen species $[79,80]$. Experimental studies suggest that these selenium systems may reduce CVD risk via several mechanisms (Table 3) [82-89]. For example, antioxidant defenses may reduce vascular and tissue injury resulting from formation of reactive oxygen species due to shear stress, hypoxia, hypertension, hyperlipidemia, and diabetes [82]. Selenium-related systems may also decrease the oxidation of lipids and protect the vascular endothelium from damage due to oxidized LDL cholesterol particles [83,84]. Selenium compounds may also more directly influence myocardial function and response to injury. In animal studies, selenium consumption increases cardiomyocyte glutathione peroxidase activity [85-87], improves cardiac recovery from ischemia-reperfusion injury [86], limits ischemia-induced structural alterations of mitochondria and sarcomeres [86], and reduces myocardial infarct size [87]. In diabetic animals, selenium improves cardiac mechanical and electrical dysfunction by restoring the cardiomyocyte glutathione redox cycle and restoring altered potassium currents [88]. Selenium also prevents myocyte structural abnormalities induced by diabetes, such as myofibril loss, reduction in myocyte diameter, and myofilament degeneration [89]. Selenium-intake also markedly reduces the incidence of ischemia-induced ventricular arrhythmias in rats [85].

Table 3. Experimentally-observed effects of selenium which may reduce CVD risk.

\author{
Systemic Effects \\ Antioxidant defense against free radicals and reactive oxygen species \\ Decreased lipid peroxidation \\ Protection against vascular damage from oxidized LDL cholesterol particles \\ Antithrombotic effects from decreased plasma thromboxane A2

\section{Direct Cardiovascular Effects} \\ Increased myocardial antioxidant glutathione peroxidase activity \\ Improved cardiac recovery from ischemia-reperfusion injury \\ Limitation of ischemia-induced and diabetes-induced ultrastructural damage \\ Reduction in myocardial infarct size \\ Restoration of altered myocyte ion currents \\ Reduced incidence of ischemia-induced ventricular arrhythmias
}

As for n-3 PUFA and mercury, these experimental effects on intermediate risk factors require confirmation in studies of actual disease endpoints in humans. Variability of selenium content of foods from different regions renders selenium consumption difficult to estimate from dietary questionnaires, 
and thus measured biomarkers are optimal to allow valid and reproducible assessment of selenium intake. Selenium levels in blood or toenails provide reasonable ranking of differences in selenium consumption in a population [90]. For example, toenail selenium levels are higher with greater dietary selenium intake, assess average consumption over the prior 6 to 12 months, and are reproducible over time ( $r=0.48$ for toenail samples obtained six years apart) $[42,90]$. Toenail selenium levels are also higher among selenium supplement users, correlate in a dose-response fashion with supplement dose, and are consistent with the geographic distribution of selenium in forage crops [91].

Several studies have evaluated the relationship between selenium status and CVD endpoints, with inconsistent results. These studies have varied widely in terms of population studied, assessment of selenium exposure (e.g., blood, toenail, supplements), outcomes examined (e.g., CHD mortality, acute MI, combined CVD endpoints), and study size (ranging from 6 to 683 cases) [92]. In a prospective study among generally healthy U.S. men, no significant association was present between toenail selenium levels and total CHD events during five years follow-up (comparing extreme quintiles of selenium, the multivariate-adjusted $\mathrm{RR}$ was $0.86,95 \% \mathrm{CI}=0.55-1.32$, $\mathrm{p}$ trend $=0.75)$, but higher selenium levels were associated with a trend toward lower risk of nonfatal heart attacks $(\mathrm{RR}=0.54,95 \% \mathrm{CI}=0.31-0.93$; $\mathrm{p}$ trend $=0.07$ ) [93]. Retrospective case-control studies have generally seen stronger inverse associations between selenium levels and CVD risk than prospective studies that would be less susceptible to control selection bias. In addition to selection bias, possible limitations of some of these individual studies include low statistical power due to few numbers of events, or evaluation of combined endpoints, e.g., including elective coronary revascularization procedures as outcomes. A meta-analysis of 25 observational studies that measured blood or toenail selenium concentrations and six randomized trials that evaluated selenium supplements demonstrated a pooled relative risk for CHD of 0.43 (95\% CI $=0.29-0.66)$ in case-control studies and 0.85 (95\% CI $=0.74-0.99)$ in cohort studies, comparing the highest with the lowest selenium concentration categories, and $0.89(95 \% \mathrm{CI}=0.68-1.17)$ in randomized trials, comparing supplement users to nonusers [92]. The effect of selenium consumption on CVD risk may also be modified by duration of consumption, smoking, alcohol use, or antioxidant vitamin intake, the influences of which were not evaluated in most prior studies. Thus, while animal-experiments suggest that selenium may protect against CVD, an American Heart Association Science Advisory in 1999 concluded that "little information is available on the preventive effects of [selenium] in human populations [94]."

Selenium intake is thought to be adequate in many populations [95], which may limit detection of relations between selenium intake and disease risk. However, the threshold for adequate selenium intake is based on prevention of Keshan disease (a rare cardiomyopathy) and on secondary functional measures (such as glutathione peroxidase activity) [96]. The threshold - if any - for prevention of CVD is unknown. As described above, in one study among U.S. men, selenium levels were associated with a trend toward lower risk of nonfatal heart attacks [93], suggesting that selenium may influence cardiovascular risk even in populations with supposedly adequate intake. Nevertheless, overall, the associations of selenium intake with CVD risk, nor any potential thresholds of effect, are currently not well-established. 


\section{Interaction between Mercury, Selenium and Cardiovascular Risk}

While the relations of mercury and selenium with cardiovascular risk are controversial, perhaps the most interesting possibility is that these relations are not independent. It has long been hypothesized that selenium may protect against toxic effects of mercury, particularly organic $\mathrm{MeHg}$ [97-102]. Evidence from both in vitro studies and experiments in animals supports this concept [97-110]. Selenium protects against mercury toxicity in rats [100], mice [105], and quail [103], and against mercury-induced apoptosis in human cell lines [108]. Cardiovascular protection may be related to antioxidant effects of selenoprotein systems, which could minimize damage from mercury-induced free radicals [100]. In rats, the mercury-induced reductions in plasma and liver glutathione S-transferase activity can be alleviated by co-administration of selenium [107]. Such protection could also result from direct effects of selenium on mercury kinetics and metabolism. Reduced selenite (for example, from glutathione peroxidase activity) degrades $\mathrm{MeHg}$ to less toxic inorganic mercury [104]. Additionally, glutathione-reduced selenite (selenide) binds with mercury and plasma selenoprotein P to form a ternary complex [109], although the biologic significance of this is unclear. Interestingly, in a small randomized trial among human subjects with low selenium intake $(\mathrm{n}=23)$, selenium supplementation reduced hair mercury levels by one-third over four months [110].

Epidemiologic studies indirectly support a possible protective effect of selenium intake on cardiovascular toxicity of mercury [111]. Mercury exposure has been associated with cardiovascular risk in European populations with possibly low selenium intake [70,72], but not in a U.S. population with likely higher selenium intake [71]. However, in the only prospective study that directly evaluated this potential interaction, selenium levels did not significantly modify relations between mercury and CHD events [71], although statistical power may have been inadequate to detect an interaction.

Thus, in vitro studies and animal-experiments suggest that selenium may protect against mercury toxicity, but it is unclear whether these findings are relevant to selenium intake and mercury exposure in humans. Understanding whether selenium intake prevents the potential CVD toxicity of mercury is important both for determining the appropriate level of public health concern for mercury exposure from fish consumption in different populations and for making recommendations regarding optimal selenium intake in the U.S. and other countries. Unfortunately, the possible interaction between mercury, selenium, and cardiovascular risk has not been studied adequately to draw any firm conclusions.

\section{Polychlorinated Biphenyls (PCBs) and Dioxins}

Although the focus of this review is on n-3 PUFA, mercury, and selenium, the potential health effects of PCBs and dioxins present in some fish species merit consideration. Exposure to these contaminants has been declining steadily since the 1970s [112], when changes in regulatory policies and industry practices reduced production and emission levels, lowering levels in foods. Nevertheless, they persist in the environment and human tissues for a long time, and attention on their levels in fish species was rekindled following publication of a comprehensive analysis that farmed salmon contained higher levels of PCBs/dioxins than wild salmon [113], a result that received considerable media attention. Placed in perspective, however, the average levels in farmed salmon were low, only $2 \%$ of the FDA action level. Thus, the main finding was not that average levels of PCBs/dioxins in farmed salmon were high, but 
simply that average levels in wild salmon were even lower. Most importantly, when the potential cancer risks of the PCBs/dioxins in both farmed and wild salmon were quantitatively compared to the expected CHD benefits from the n-3 PUFA, the estimated magnitudes of the hypothesized cancer risk were orders of magnitude lower than the reduction in cardiac mortality (Figure 5) [114]. Three additional points deserve attention. First, the estimates of cancer risk were based on 70-year lifetimes of eating salmon at levels to achieve $1000 \mathrm{mg} / \mathrm{d}$ EPA+DHA, or approximately seven 3.5-oz wild salmon servings/week or three 3.5-oz farmed salmon servings/week for 70 years. However, based on the nonlinear relationship between EPA+DHA intake and CHD mortality [1], a similar CHD mortality reduction would likely occur at one-fourth of the consumption level (i.e., $250 \mathrm{mg} / \mathrm{d}$ EPA+DHA), but with only one-fourth of the cancer risk (i.e., 6 or 2 excess cancer deaths per 100,000 lifetimes for farmed or wild salmon, respectively). Second, the estimated cancer risks of PCBs/dioxins include a 10-fold uncertainty factor; i.e., the true effects at these consumption levels may be $1 / 10$ as large, or 0.6 or 0.2 excess cancer deaths per 100,000 lifetimes for farmed or wild salmon, respectively. Finally, the estimated cancer risks of PCBs/dioxins are largely derived from extrapolation of results from limited high human exposures and animal-experiments, whereas the calculated benefits for CHD death are derived from multiple large prospective cohort studies and randomized controlled clinical trials in humans of fish and n-3 PUFA consumption and actual CHD mortality $[1,114]$. Thus, whether the true excess cancer risk for 70 -years consumption of farmed or wild salmon would be 24 or 8,6 or 2, or 0.6 or 0.2 deaths per 100,000 lifetimes, these risks pale in comparison, both in magnitude and strength of evidence, to the many thousands of CHD deaths that would be prevented by such consumption. Because levels of PCBs/dioxins may be higher in some freshwater fish species caught in certain local rivers or lakes, sports fishermen who regularly consume locally caught freshwater fish should consult local advisories. However, for commercially purchased fish and shellfish, based on the relatively low contents of PCBs/dioxins [1], the greater strength and quality of evidence for CHD benefits of n-3 PUFA vs. cancer risks of PCBs/dioxins, and the quantitatively far larger CHD benefits compared with the hypothesized cancer risks, the great majority of individuals who consume commercially purchased fish should not be concerned about PCB or dioxin content in making fish consumption decisions; indeed, such concern may substantially increase health risk by leading to reduced fish consumption. Continued attention to reducing $\mathrm{PCB}$ and dioxin emissions into the environment is important, but in contrast to $\mathrm{MeHg}$ exposure, this is not a seafood-specific issue: the majority (> 90\%) of PCBs and dioxins in the food supply are consumed from non-seafood sources, in particular meats, dairy products, and vegetables $[115,116]$. 
Figure 5. Calculated cancer risks vs. cardiac benefits from a lifetime of regular consumption of farmed or wild salmon, based on contents of PCBs/dioxins and n-3 PUFA in farmed and wild salmon [114]. The estimated cancer risks - 24 vs. 8 deaths for farmed vs. wild salmon, respectively - are orders of magnitude smaller than the calculated cardiac benefits of 7,125 fewer cardiac deaths for either farmed or wild salmon consumption.

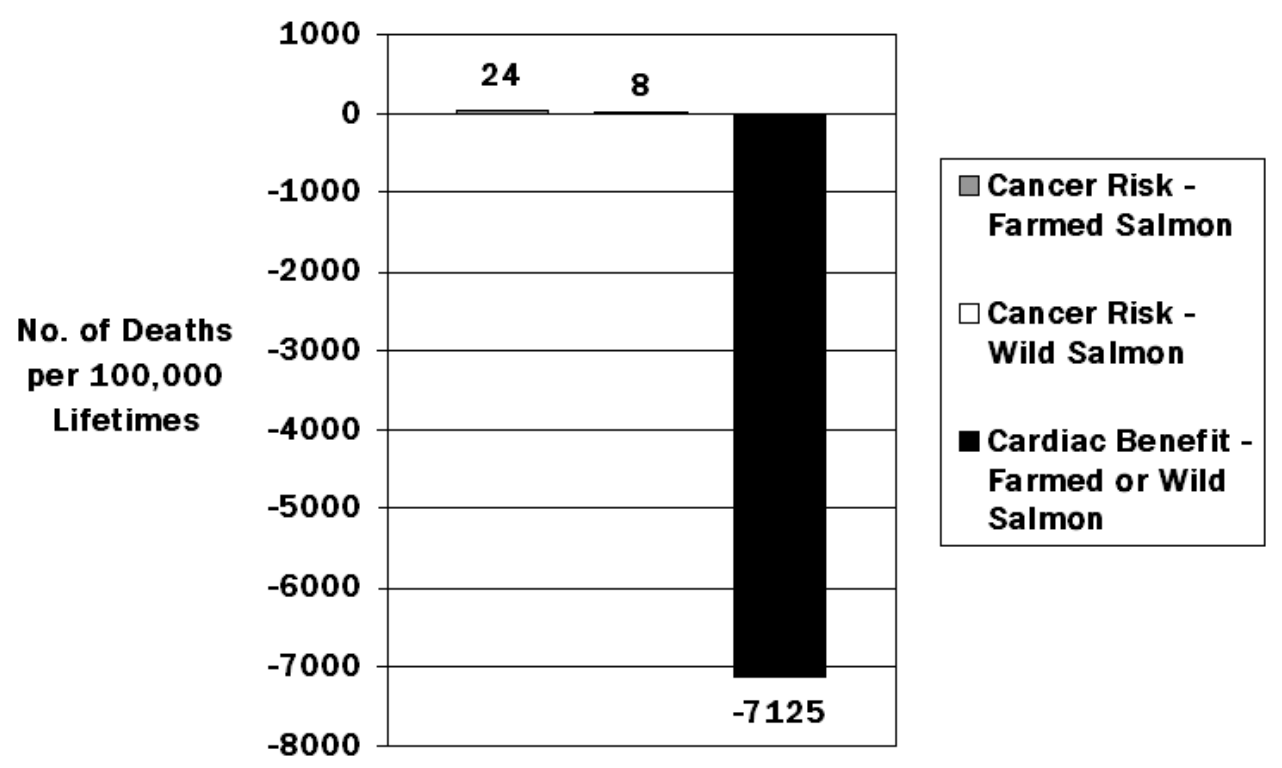

\section{Conclusions}

Consistent evidence from human experimental studies, case-control studies, prospective cohort studies, and randomized controlled trials indicates that modest consumption of fish significantly reduces cardiac death. The magnitude of benefit is substantial, with $36 \%$ lower risk with consumption of $250 \mathrm{mg} / \mathrm{d}$ EPA+DHA (equivalent to $1-2$ servings of fatty fish per week), compared with no intake. The strength, quality, and consistency of evidence for health effects of chronic low-level mercury exposure in adults are much less robust, indicating a need for further investigation of possible effects of such exposure on disease outcomes in appropriately powered prospective human studies. The conflicting results of prior studies of mercury and CVD risk are not dose-related, as some studies with relatively low exposures observed a positive association, whereas other studies found no significant associations at similar or higher exposures. Notably, even in the two studies that observed a positive relationship between mercury exposure and cardiovascular risk, the overall average effect of fish consumption was protective: mercury exposure appeared to lessen, but not reverse, the cardiovascular protection of fish intake. Animal-experiments suggest that selenium may protect against CVD, but studies of selenium intake and cardiovascular endpoints in humans are inconsistent, and a possible interaction between mercury and selenium for CVD risk has not been adequately studied in humans. Based on the current evidence, the health risks for adults of not consuming fish outweigh potential risks from mercury or other contaminants. Modest consumption (1-2 fish servings per week) appears to provide most of the reduction in CHD mortality, and concerns over possible accompanying effects of mercury or other contaminants in adults can be curtailed by simply choosing a variety of different fish and seafood [1,11]. 
Several unanswered questions remain. First, growing evidence suggests that fish consumption has benefits for health outcomes beyond CHD mortality, including nonfatal cardiovascular events and several noncardiovascular outcomes: these potential effects, and their dose-responses, require further investigation. Second, whereas current evidence does not support a need for any advisory to limit intake of fish or specific fish species for health effects in adults, further research is needed to elucidate the potential health effects of mercury exposure and the level, if any, at which potential effects of mercury could equal or outweigh the benefits from n-3 PUFA consumption. Even if further research ultimately confirms that, as suggested by current evidence, the net health effect of any single fish meal is nearly always beneficial, the extent to which mercury might reduce this net benefit must be evaluated to inform regulatory decisions regarding control of mercury emissions, in that greater public health benefit may be derived from fish consumption if mercury levels were decreased further. Third, whether selenium protects against CVD risk and/or against potential toxic effects of mercury, as well as any threshold of such effects, must be better established. Finally, although not a focus of this present review, both the intended and unanticipated consequences of government advisories, public health recommendations, and media reports regarding health effects of fish consumption must be better understood, so that well-intentioned messages do not cause confusion or ultimate harm. The answers to these questions will have significant implications for our understanding of how n-3 PUFA, mercury, and selenium influence health risk and will clarify the most appropriate emphases for recommendations regarding fish intake to improve health in adults. As future studies are completed, continued careful consideration of the strength and consistency of the evidence, as well as the relative magnitudes of effect, is imperative.

\section{Acknowledgments}

I am grateful for past reviews by Dr. Rafael Diaz-Flores and Dr. Hooman Hajian on environmental sources and experimental effects of mercury and selenium. I thank Dr. Eric Rimm and Dr. David Siscovick for their friendship, support, and elucidating conversations and collaborations.

Supported by the Searle Scholar Award from the Searle Funds at The Chicago Community Trust. The funding source had no role in study design; in the collection, analysis, or interpretation of data; in the writing of the report; or in the decision to submit the paper for publication.

Disclosures: Research grants (significant) from NHLBI and NIEHS (K08 HL 075628-01, R01 HL 085710-01, R01 ES 014433-01A2); the Searle Scholar Award from the Searle Funds at The Chicago Community Trust; the Genes and Environment Initiative at the Harvard School of Public Health; the Gates Foundation/World Health Organization Global Burden of Diseases, Injuries, and Risk Factors Study; and GSK, Sigma Tau, and Pronova for an investigator-initiated trial of fish oil to prevent post-surgical arrhythmia. Honoraria (modest) for speaking at scientific conferences and reviewing on topics related to diet and cardiovascular disease, including from the U.S. Food and Drug Administration, United Nations, World Health Organization, UpToDate, International Life Sciences Institute, Aramark, and several universities and scientific organizations. No ownership, patents, stocks, advisory board membership, nor speaking board membership. 


\section{References}

1. Mozaffarian, D.; Rimm, E.B. Fish intake, contaminants, and human health: evaluating the risks and the benefits. JAMA 2006, 296, 1885-1899.

2. Mahaffey, K.R. Methylmercury: a new look at the risks. Public Health Rep. 1999, 114, 396-399, 402-413.

3. Committee on the Toxicological Effects of Methylmercury; Board on Environmental Studies and Toxicology; Commission on Life Sciences; National Research Council. Toxicological Effects of Methylmercury; National Academy Press: Washington, DC, USA, 2000.

4. Rice, D.C.; Schoeny, R.; Mahaffey, K. Methods and rationale for derivation of a reference dose for methylmercury by the U.S. EPA. Risk Anal. 2003, 23, 107-115.

5. Rice, D.C. The US EPA reference dose for methylmercury: sources of uncertainty. Environ. Res. 2004, 95, 406-413.

6. Chan, H.M.; Egeland, G.M. Fish consumption, mercury exposure, and heart diseases. Nutr. Rev. 2004, 62, 68-72.

7. U.S. Environmental Protection Agency. Mercury Study Report to Congress. Available online: http://www.epa.gov/mercury/report.htm (accessed January 24, 2006).

8. Gochfeld, M. Cases of mercury exposure, bioavailability, and absorption. Ecotoxicol. Environ. Saf. 2003, 56, 174-179.

9. Risher, J.F. Too much of a good thing (fish): methylmercury case study. J. Environ. Health 2004, 67, 9-14, 28.

10. Mozaffarian, D. Does alpha-linolenic acid intake reduce the risk of coronary heart disease? A review of the evidence. Altern. Ther. Health Med. 2005, 11, 24-30.

11. Institute of Medicine of the National Acadamies. Seafood Choices: Balancing Benefits and Risks. 2006. Available online: http://www.iom.edu/CMS/3788/23788/37679.aspx (accessed January 18, 2008).

12. U.S. Department of Health and Human Services; U.S. Food and Drug Administration. What You Need to Know About Mercury in Fish and Shellfish: 2004 EPA and FDA Advice for women who might become pregnant, women who are pregnant, nursing mothers, young children. Available online: http://www.cfsan.fda.gov/ dms/admehg3.html (accessed January 14, 2008).

13. Leaf, A.; Kang, J.X.; Xiao, Y.F.; Billman, G.E. Clinical prevention of sudden cardiac death by n-3 polyunsaturated fatty acids and mechanism of prevention of arrhythmias by n-3 fish oils. Circulation 2003, 107, 2646-2652.

14. McLennan, P.L. Myocardial membrane fatty acids and the antiarrhythmic actions of dietary fish oil in animal models. Lipids 2001, 36, S111-114.

15. Charnock, J.S.; McLennan, P.L.; Abeywardena, M.Y. Dietary modulation of lipid metabolism and mechanical performance of the heart. Mol. Cell Biochem. 1992, 116, 19-25.

16. Kenny, D.; Warltier, D.C.; Pleuss, J.A.; Hoffmann, R.G.; Goodfriend, T.L.; Egan, B.M. Effect of omega-3 fatty acids on the vascular response to angiotensin in normotensive men. Am. J. Cardiol. 1992, 70, 1347-1352.

17. Chin, J.P.; Gust, A.P.; Nestel, P.J.; Dart, A.M. Marine oils dose-dependently inhibit vasoconstriction of forearm resistance vessels in humans. Hypertension 1993, 21, 22-28. 
18. Geleijnse, J.M.; Giltay, E.J.; Grobbee, D.E.; Donders, A.R.; Kok, F.J. Blood pressure response to fish oil supplementation: metaregression analysis of randomized trials. J. Hypertens. 2002, 20, 1493-1499.

19. Mozaffarian, D.; Geelen, A.; Brouwer, I.A.; Geleijnse, J.M.; Zock, P.L.; Katan, M.B. Effect of fish oil on heart rate in humans: A meta-analysis of randomized controlled trials. Circulation 2005, 112, 1945-1952.

20. Mozaffarian, D.; Gottdiener, J.S.; Siscovick, D.S. Intake of tuna or other broiled or baked fish vs. fried fish and cardiac structure, function, and hemodynamics. Am. J. Cardiol. 2006, 97, 216-222.

21. Nestel, P.J. Fish oil and cardiovascular disease: lipids and arterial function. Am. J. Clin. Nutr. 2000, 71, 228S-231S.

22. Christensen, J.H. n-3 fatty acids and the risk of sudden cardiac death. Emphasis on heart rate variability. Dan. Med. Bull. 2003, 50, 347-367.

23. Mori, T.A.; Beilin, L.J. Omega-3 fatty acids and inflammation. Curr. Atheroscler. Rep. 2004, 6, 461-467.

24. Kristensen, S.D.; Iversen, A.M.; Schmidt, E.B. n-3 polyunsaturated fatty acids and coronary thrombosis. Lipids 2001, 36 Suppl, S79-82.

25. Clandinin, M.T.; Cheema, S.; Field, C.J.; Garg, M.L.; Venkatraman, J.; Clandinin, T.R. Dietary fat: exogenous determination of membrane structure and cell function. Faseb. J. 1991, 5, 2761-2769.

26. Feller, S.E.; Gawrisch, K. Properties of docosahexaenoic-acid-containing lipids and their influence on the function of rhodopsin. Curr. Opin. Struct. Biol. 2005, 15, 416-422.

27. Vanden Heuvel, J.P. Diet, fatty acids, and regulation of genes important for heart disease. Curr. Atheroscler. Rep. 2004, 6, 432-440.

28. Oomen, C.M.; Feskens, E.J.; Rasanen, L.; Fidanza, F.; Nissinen, A.M.; Menotti, A.; Kok, F.J.; Kromhout, D. Fish consumption and coronary heart disease mortality in Finland, Italy, and The Netherlands. Am. J. Epidemiol. 2000, 151, 999-1006.

29. Mozaffarian, D.; Lemaitre, R.N.; Kuller, L.H.; Burke, G.L.; Tracy, R.P.; Siscovick, D.S. Cardiac benefits of fish consumption may depend on the type of fish meal consumed: the Cardiovascular Health Study. Circulation 2003, 107, 1372-1377.

30. Harris, W.S.; Mozaffarian, D.; Lefevre, M.; Toner, C.D.; Colombo, J.; Cunnane, S.C.; Holden, J.M.; Klurfeld, D.M.; Morris, M.C.; Whelan, J. Towards establishing dietary reference intakes for eicosapentaenoic and docosahexaenoic acids. J. Nutr. 2009, 139, 804S-819S.

31. Sun, Q.; Ma, J.; Campos, H.; Rexrode, K.M.; Albert, C.M.; Mozaffarian, D.; Hu, F.B. Blood concentrations of individual long-chain n-3 fatty acids and risk of nonfatal myocardial infarction. Am. J. Clin. Nutr. 2008, 88, 216-223.

32. He, K.; Song, Y.; Daviglus, M.L.; Liu, K.; Van Horn, L.; Dyer, A.R.; Goldbourt, U.; Greenland, P. Fish consumption and incidence of stroke: a meta-analysis of cohort studies. Stroke 2004, 35, 1538-1542.

33. Mozaffarian, D.; Psaty, B.M.; Rimm, E.B.; Lemaitre, R.N.; Burke, G.L.; Lyles, M.F.; Lefkowitz, D.; Siscovick, D.S. Fish intake and risk of incident atrial fibrillation. Circulation 2004, 110, 368-373. 
34. Morris, M.C.; Evans, D.A.; Tangney, C.C.; Bienias, J.L.; Wilson, R.S. Fish consumption and cognitive decline with age in a large community study. Arch. Neurol. 2005, 62, 1849-1853.

35. Lin, P.Y.; Su, K.P. A meta-analytic review of double-blind, placebo-controlled trials of antidepressant efficacy of omega-3 fatty acids. J. Clin. Psychiatry 2007, 68, 1056-1061.

36. U.S. Food and Drug Administration. Mercury in fish: Cause for concern? Available online: http://www.fda.gov/fdac/reprints/mercury.html (accessed January 14, 2008).

37. The Risk Assessment Information System. Toxicity Summary for Mercury. Available online: http://risk.lsd.ornl.gov/tox/profiles/mercury_f_V1.shtml (accessed January 14, 2008).

38. U.S. Geological Survey. Mercury in the Environment. Available online: http://www.usgs.gov/ themes/factsheet/146-00/ (accessed October 25, 2005).

39. Hightower, J.M.; Moore, D. Mercury levels in high-end consumers of fish. Environ. Health Perspect 2003, 111, 604-608.

40. Joshi, A.; Douglass, C.W.; Kim, H.D.; Joshipura, K.J.; Park, M.C.; Rimm, E.B.; Carino, M.J.; Garcia, R.I.; Morris, J.S.; Willett, W.C. The relationship between amalgam restorations and mercury levels in male dentists and nondental health professionals. J. Public Health Dent. 2003, $63,52-60$.

41. MacIntosh, D.L.; Williams, P.L.; Hunter, D.J.; Sampson, L.A.; Morris, S.C.; Willett, W.C.; Rimm, E.B. Evaluation of a food frequency questionnaire-food composition approach for estimating dietary intake of inorganic arsenic and methylmercury. Cancer Epidemiol. Biomarkers Prev. 1997, 6, 1043-1050.

42. Garland, M.; Morris, J.S.; Rosner, B.A.; Stampfer, M.J.; Spate, V.L.; Baskett, C.J.; Willett, W.C.; Hunter, D.J. Toenail trace element levels as biomarkers: reproducibility over a 6-year period. Cancer Epidemiol. Biomarkers Prev. 1993, 2, 493-497.

43. Rosner, B.; Hennekens, C.H.; Kass, E.H.; Miall, W.E. Age-specific correlation analysis of longitudinal blood pressure data. Am. J. Epidemiol. 1977, 106, 306-313.

44. Berglund, M.; Lind, B.; Bjornberg, K.A.; Palm, B.; Einarsson, O.; Vahter, M. Inter-individual variations of human mercury exposure biomarkers: a cross-sectional assessment. Environ. Health 2005, 4, 20.

45. Lebel, J.; Mergler, D.; Branches, F.; Lucotte, M.; Amorim, M.; Larribe, F.; Dolbec, J. Neurotoxic effects of low-level methylmercury contamination in the Amazonian Basin. Environ. Res. 1998, 79, 20-32.

46. Yokoo, E.M.; Valente, J.G.; Grattan, L.; Schmidt, S.L.; Platt, I.; Silbergeld, E.K. Low level methylmercury exposure affects neuropsychological function in adults. Environ. Health 2003, 2,8 .

47. Auger, N.; Kofman, O.; Kosatsky, T.; Armstrong, B. Low-level methylmercury exposure as a risk factor for neurologic abnormalities in adults. Neurotoxicology 2005, 26, 149-157.

48. Weil, M.; Bressler, J.; Parsons, P.; Bolla, K.; Glass, T.; Schwartz, B. Blood mercury levels and neurobehavioral function. JAMA 2005, 293, 1875-1882.

49. Johansson, N.; Basun, H.; Winblad, B.; Nordberg, M. Relationship between mercury concentration in blood, cognitive performance, and blood pressure, in an elderly urban population. Biometals 2002, 15, 189-195. 
50. Peet, M.; Stokes, C. Omega-3 fatty acids in the treatment of psychiatric disorders. Drugs 2005, 65, 1051-1059.

51. Young, G.; Conquer, J. Omega-3 fatty acids and neuropsychiatric disorders. Reprod Nutr. Dev. 2005, 45, 1-28.

52. Wakita, Y. Hypertension induced by methyl mercury in rats. Toxicol. Appl. Pharmacol. 1987, 89, 144-147.

53. Kostka, B.; Michalska, M.; Krajewska, U.; Wierzbicki, R. Blood coagulation changes in rats poisoned with methylmercuric chloride (MeHg). Pol. J. Pharmacol. Pharm. 1989, 41, 183-189.

54. Halbach, S. Mercury compounds: lipophilicity and toxic effects on isolated myocardial tissue. Arch. Toxicol. 1990, 64, 315-319.

55. Rungby, J.; Ernst, E. Experimentally induced lipid peroxidation after exposure to chromium, mercury or silver: interactions with carbon tetrachloride. Pharmacol. Toxicol. 1992, 70, 205-207.

56. Jansson, G.; Harms-Ringdahl, M. Stimulating effects of mercuric- and silver ions on the superoxide anion production in human polymorphonuclear leukocytes. Free Radic. Res. Commun. 1993, 18, 87-98.

57. Oliveira, E.M.; Vassallo, D.V.; Sarkis, J.J.; Mill, J.G. Mercury effects on the contractile activity of isolated heart muscle. Toxicol. Appl. Pharmacol. 1994, 128, 86-91.

58. InSug, O.; Datar, S.; Koch, C.J.; Shapiro, I.M.; Shenker, B.J. Mercuric compounds inhibit human monocyte function by inducing apoptosis: evidence for formation of reactive oxygen species, development of mitochondrial membrane permeability transition and loss of reductive reserve. Toxicology 1997, 124, 211-224.

59. da Cunha, V.; Souza, H.P.; Rossoni, L.V.; Franca, A.S.; Vassallo, D.V. Effects of mercury on the isolated perfused rat tail vascular bed are endothelium-dependent. Arch. Environ. Contam. Toxicol. 2000, 39, 124-130.

60. de Assis, G.P.; Silva, C.E.; Stefanon, I.; Vassallo, D.V. Effects of small concentrations of mercury on the contractile activity of the rat ventricular myocardium. Comp. Biochem. Physiol. C Toxicol. Pharmacol. 2003, 134, 375-383.

61. Moreira, C.M.; Oliveira, E.M.; Bonan, C.D.; Sarkis, J.J.; Vassallo, D.V. Effects of mercury on myosin ATPase in the ventricular myocardium of the rat. Comp. Biochem. Physiol. C Toxicol. Pharmacol. 2003, 135C, 269-275.

62. Sorensen, N.; Murata, K.; Budtz-Jorgensen, E.; Weihe, P.; Grandjean, P. Prenatal methylmercury exposure as a cardiovascular risk factor at seven years of age. Epidemiology 1999, 10, 370-375.

63. Grandjean, P.; Murata, K.; Budtz-Jorgensen, E.; Weihe, P. Cardiac autonomic activity in methylmercury neurotoxicity: 14-year follow-up of a Faroese birth cohort. J Pediatr 2004, 144, 169-176.

64. Thurston, S.W.; Bovet, P.; Myers, G.J.; Davidson, P.W.; Georger, L.A.; Shamlaye, C.; Clarkson, T.W. Does prenatal methylmercury exposure from fish consumption affect blood pressure in childhood? Neurotoxicology 2007, 28, 924-930.

65. Fillion, M.; Mergler, D.; Sousa Passos, C.J.; Larribe, F.; Lemire, M.; Guimaraes, J.R. A preliminary study of mercury exposure and blood pressure in the Brazilian Amazon. Environ. Health 2006, 5, 29. 
66. Valera, B.; Dewailly, E.; Poirier, P. Cardiac autonomic activity and blood pressure among Nunavik Inuit adults exposed to environmental mercury: a cross-sectional study. Environ. Health 2008, 7, 29.

67. Choi, A.L.; Weihe, P.; Budtz-Jorgensen, E.; Jorgensen, P.J.; Salonen, J.T.; Tuomainen, T.P.; Murata, K.; Nielsen, H.P.; Petersen, M.S.; Askham, J.; Grandjean, P. Methylmercury exposure and adverse cardiovascular effects in Faroese whaling men. Environ. Health Perspect 2009, 117, 367-372.

68. Ahlqwist, M.; Bengtsson, C.; Lapidus, L.; Gergdahl, I.A.; Schutz, A. Serum mercury concentration in relation to survival, symptoms, and diseases: results from the prospective population study of women in Gothenburg, Sweden. Acta Odontol Scand 1999, 57, 168-174.

69. Hallgren, C.G.; Hallmans, G.; Jansson, J.H.; Marklund, S.L.; Huhtasaari, F.; Schutz, A.; Stromberg, U.; Vessby, B.; Skerfving, S. Markers of high fish intake are associated with decreased risk of a first myocardial infarction. Br. J. Nutr. 2001, 86, 397-404.

70. Guallar, E.; Sanz-Gallardo, M.I.; van't Veer, P.; Bode, P.; Aro, A.; Gomez-Aracena, J.; Kark, J.D.; Riemersma, R.A.; Martin-Moreno, J.M.; Kok, F.J. Mercury, fish oils, and the risk of myocardial infarction. N. Engl. J. Med. 2002, 347, 1747-1754.

71. Yoshizawa, K.; Rimm, E.B.; Morris, J.S.; Spate, V.L.; Hsieh, C.C.; Spiegelman, D.; Stampfer, M.J.; Willett, W.C. Mercury and the risk of coronary heart disease in men. N. Engl. J. Med. 2002, 347, 1755-1760.

72. Virtanen, J.K.; Voutilainen, S.; Rissanen, T.H.; Mursu, J.; Tuomainen, T.P.; Korhonen, M.J.; Valkonen, V.P.; Seppanen, K.; Laukkanen, J.A.; Salonen, J.T. Mercury, fish oils, and risk of acute coronary events and cardiovascular disease, coronary heart disease, and all-cause mortality in men in eastern Finland. Arterioscler. Thromb. Vasc. Biol. 2005, 25, 228-233.

73. Wennberg, M.; Bergdahl, I.A.; Stegmayr, B.; Hallmans, G.; Lundh, T.; Skerfving, S.; Stromberg, U.; Vessby, B.; Jansson, J.H. Fish intake, mercury, long-chain n-3 polyunsaturated fatty acids and risk of stroke in northern Sweden. Br. J. Nutr. 2007, 98, 1038-1045.

74. Thom, T.; Haase, N.; Rosamond, W.; Howard, V.J.; Rumsfeld, J.; Manolio, T.; Zheng, Z.J.; Flegal, K.; O'Donnell, C.; Kittner, S.; Lloyd-Jones, D.; Goff, D.C., Jr.; Hong, Y.; Adams, R.; Friday, G.; Furie, K.; Gorelick, P.; Kissela, B.; Marler, J.; Meigs, J.; Roger, V.; Sidney, S.; Sorlie, P.; Steinberger, J.; Wasserthiel-Smoller, S.; Wilson, M.; Wolf, P. Heart disease and stroke statistics-2006 update: a report from the American Heart Association Statistics Committee and Stroke Statistics Subcommittee. Circulation 2006, 113, e85-151.

75. Konig, A.; Bouzan, C.; Cohen, J.T.; Connor, W.E.; Kris-Etherton, P.M.; Gray, G.M.; Lawrence, R.S.; Savitz, D.A.; Teutsch, S.M. A quantitative analysis of fish consumption and coronary heart disease mortality. Am. J. Prev. Med. 2005, 29, 335-346.

76. Mozaffarian, D.; Rimm, E.B. Methylmercury and risk in adults - A balanced view, and more research, are needed. Environ. Health 2007, 6, 31.

77. Rissanen, T.; Voutilainen, S.; Nyyssonen, K.; Lakka, T.A.; Salonen, J.T. Fish oil-derived fatty acids, docosahexaenoic acid and docosapentaenoic acid, and the risk of acute coronary events: the Kuopio ischaemic heart disease risk factor study. Circulation 2000, 102, 2677-2679.

78. Levander, O.A. A global view of human selenium nutrition. Annu. Rev. Nutr. 1987, 7, 227-250. 
79. Holben, D.H.; Smith, A.M. The diverse role of selenium within selenoproteins: a review. J. Am. Diet. Assoc. 1999, 99, 836-843.

80. Brown, K.M.; Arthur, J.R. Selenium, selenoproteins and human health: a review. Public Health Nutr. 2001, 4, 593-599.

81. National Institutes of Health; Office of Dietary Supplements. Dietary supplement fact sheet: Selenium. Available online: http://ods.od.nih.gov/factsheets/selenium.asp (accessed January 14, 2008).

82. Li, J.M.; Shah, A.M. Endothelial cell superoxide generation: regulation and relevance for cardiovascular pathophysiology. Am. J. Physiol. Regul. Integr. Comp. Physiol. 2004, 287, R1014-1030.

83. Huang, K.; Liu, H.; Chen, Z.; Xu, H. Role of selenium in cytoprotection against cholesterol oxide-induced vascular damage in rats. Atherosclerosis 2002, 162, 137-144.

84. Traulsen, H.; Steinbrenner, H.; Buchczyk, D.P.; Klotz, L.O.; Sies, H. Selenoprotein P protects low-density lipoprotein against oxidation. Free Radic. Res. 2004, 38, 123-128.

85. Tanguy, S.; Boucher, F.; Besse, S.; Ducros, V.; Favier, A.; de Leiris, J. Trace elements and cardioprotection: increasing endogenous glutathione peroxidase activity by oral selenium supplementation in rats limits reperfusion-induced arrhythmias. J. Trace Elem. Med. Biol. 1998, 12, 28-38.

86. Tanguy, S.; Toufektsian, M.C.; Besse, S.; Ducros, V.; De Leiris, J.; Boucher, F. Dietary selenium intake affects cardiac susceptibility to ischaemia/reperfusion in male senescent rats. Age Ageing 2003, 32, 273-278.

87. Tanguy, S.; Morel, S.; Berthonneche, C.; Toufektsian, M.C.; de Lorgeril, M.; Ducros, V.; Tosaki, A.; de Leiris, J.; Boucher, F. Preischemic selenium status as a major determinant of myocardial infarct size in vivo in rats. Antioxid. Redox. Signal 2004, 6, 792-796.

88. Ayaz, M.; Ozdemir, S.; Ugur, M.; Vassort, G.; Turan, B. Effects of selenium on altered mechanical and electrical cardiac activities of diabetic rat. Arch. Biochem. Biophys. 2004, 426, 83-90.

89. Ayaz, M.; Can, B.; Ozdemir, S.; Turan, B. Protective effect of selenium treatment on diabetes-induced myocardial structural alterations. Biol. Trace Elem. Res. 2002, 89, 215-226.

90. Longnecker, M.P.; Stram, D.O.; Taylor, P.R.; Levander, O.A.; Howe, M.; Veillon, C.; McAdam, P.A.; Patterson, K.Y.; Holden, J.M.; Morris, J.S.; Swanson, C.A.; Willett, W.C. Use of selenium concentration in whole blood, serum, toenails, or urine as a surrogate measure of selenium intake. Epidemiology 1996, 7, 384-390.

91. Hunter, D.J.; Morris, J.S.; Chute, C.G.; Kushner, E.; Colditz, G.A.; Stampfer, M.J.; Speizer, F.E.; Willett, W.C. Predictors of selenium concentration in human toenails. Am. J. Epidemiol. 1990, $132,114-122$.

92. Flores-Mateo, G.; Navas-Acien, A.; Pastor-Barriuso, R.; Guallar, E. Selenium and coronary heart disease: a meta-analysis. Am. J. Clin. Nutr. 2006, 84, 762-773.

93. Yoshizawa, K.; Ascherio, A.; Morris, J.S.; Stampfer, M.J.; Giovannucci, E.; Baskett, C.K.; Willett, W.C.; Rimm, E.B. Prospective study of selenium levels in toenails and risk of coronary heart disease in men. Am. J. Epidemiol. 2003, 158, 852-860. 
94. Tribble, D.L. AHA Science Advisory. Antioxidant consumption and risk of coronary heart disease: emphasison vitamin $\mathrm{C}$, vitamin $\mathrm{E}$, and beta-carotene: A statement for healthcare professionals from the American Heart Association. Circulation 1999, 99, 591-595.

95. Burk, R.F. Selenium, an antioxidant nutrient. Nutr. Clin. Care 2002, 5, 75-79.

96. Levander, O.A. Selenium requirements as discussed in the 1996 joint FAO/IAEA/WHO expert consultation on trace elements in human nutrition. Biomed. Environ. Sci. 1997, 10, 214-219.

97. Parizek, J.; Ostadalova, I. The protective effect of small amounts of selenite in sublimate intoxication. Experientia 1967, 23, 142-143.

98. Ganther, H.E.; Goudie, C.; Sunde, M.L.; Kopecky, M.J.; Wagner, P. Selenium: relation to decreased toxicity of methylmercury added to diets containing tuna. Science 1972, 175, 1122-1124.

99. Skerfving, S. Interaction between selenium and methylmercury. Environ. Health Perspect 1978, 25, 57-65.

100. Ganther, H.E. Modification of methylmercury toxicity and metabolism by selenium and vitamin E: possible mechanisms. Environ. Health Perspect 1978, 25, 71-76.

101. Cuvin-Aralar, M.L.; Furness, R.W. Mercury and selenium interaction: a review. Ecotoxicol. Environ. Saf. 1991, 21, 348-364.

102. Watanabe, C. Modification of mercury toxicity by selenium: practical importance? Tohoku. J. Exp. Med. 2002, 196, 71-77.

103. Stoewsand, G.S.; Bache, C.A.; Lisk, D.J. Dietary selenium protection of methylmercury intoxication of Japanese quail. Bull. Environ. Contam. Toxicol. 1974, 11, 152-156.

104. Iwata, H.; Masukawa, T.; Kito, H.; Hayashi, M. Degradation of methylmercury by selenium. Life Sci. 1982, 31, 859-866.

105. Iwata, H.; Masukawa, T.; Kito, H.; Hayashi, M. Degradation of methylmercury by selenium. Life Sci. 1982, 31, 859-866.

106. Goyer, R.A. Nutrition and metal toxicity. Am. J. Clin. Nutr. 1995, 61, 646S-650S.

107. El-Demerdash, F.M. Effects of selenium and mercury on the enzymatic activities and lipid peroxidation in brain, liver, and blood of rats. J. Environ. Sci. Health B 2001, 36, 489-499.

108. Frisk, P.; Wester, K.; Yaqob, A.; Lindh, U. Selenium protection against mercury-induced apoptosis and growth inhibition in cultured K-562 cells. Biol. Trace Elem. Res. 2003, 92, 105-114.

109. Sasakura, C.; Suzuki, K.T. Biological interaction between transition metals (Ag, Cd and Hg), selenide/sulfide and selenoprotein P. J. Inorg. Biochem. 1998, 71, 159-162.

110. Seppanen, K.; Kantola, M.; Laatikainen, R.; Nyyssonen, K.; Valkonen, V.P.; Kaarlopp, V.; Salonen, J.T. Effect of supplementation with organic selenium on mercury status as measured by mercury in pubic hair. J. Trace. Elem. Med. Biol. 2000, 14, 84-87.

111. Buettner, C. Mercury and the risk of myocardial infarction. N. Engl. J. Med. 2003, 348, 2151-2154.

112. Aylward, L.L.; Hays, S.M. Temporal trends in human TCDD body burden: decreases over three decades and implications for exposure levels. J. Expo. Anal. Environ. Epidemiol. 2002, 12, 319-328.

113. Hites, R.A.; Foran, J.A.; Carpenter, D.O.; Hamilton, M.C.; Knuth, B.A.; Schwager, S.J. Global assessment of organic contaminants in farmed salmon. Science 2004, 303, 226-229. 
114. Foran, J.A.; Good, D.H.; Carpenter, D.O.; Hamilton, M.C.; Knuth, B.A.; Schwager, S.J. Quantitative analysis of the benefits and risks of consuming farmed and wild salmon. J. Nutr. 2005, 135, 2639-2643.

115. Schecter, A.; Cramer, P.; Boggess, K.; Stanley, J.; Papke, O.; Olson, J.; Silver, A.; Schmitz, M. Intake of dioxins and related compounds from food in the U.S. population. J. Toxicol. Environ. Health A 2001, 63, 1-18.

116. Judd, N.; Griffith, W.C.; Faustman, E.M. Contribution of PCB exposure from fish consumption to total dioxin-like dietary exposure. Regul. Toxicol. Pharmacol. 2004, 40, 125-135.

(C) 2009 by the authors; licensee Molecular Diversity Preservation International, Basel, Switzerland. This article is an open-access article distributed under the terms and conditions of the Creative Commons Attribution license (http://creativecommons.org/licenses/by/3.0/). 